\title{
V CONGRESO NACIONAL DE ALIANZA POPULAR
}

Durante los días 20 y 21 del mes de febrero de 1982 tuvo lugar el desarrollo del V Congreso Nacional de Alianza Popular, celebrado en el Palacio de Exposiciones y Congresos de Madrid. El Congreso tuvo lugar en un momento especial para Alianza Popular, ya que, por una parte, la celebración de las elecciones gallegas había supuesto un respaldo mayoritario a esta opción política, de una forma manifiesta, después de una serie de resultados poco brillantes en anteriores elecciones españolas (nacionales y regionales), y por otra, este Congreso tenía que hacer frente ya a un encuadramiento determinativo de la opción política de Alianza Popular tanto de cara a las elecciones andaluzas, consideradas en muchos sectores políticos como un verdadero test de consecuencias nacionales, como, por otra parte, respecto a las elecciones generales a un año vista.

El entorno en el que el Congreso se desarrolló estuvo caracterizado por los siguientes factores:

- Comienzo del desarrollo del juicio por el intento de golpe de 1981.

- La especial coyuntura de UCD como partido de gobierno.

- El desencanto político en grandes sectores del país.

- La crisis económica y el terrorismo que no encuentran una definitiva solución.

A estos puntos genéricos que afectan al espectro político general del país debemos agregar los propios del partido, caracterizados por:

- Un afianzamiento progresivo de su militancia política.

- La mayoría relativa conseguida en las elecciones gallegas.

- Su definición como opción de centro-derecha, dentro del marco constitucional, en una insistencia de tender a la formación de la denominada mayoría natural.

Esta situación había generado en el partido:

- Un afianzamiento de la cohesión interna y del liderazgo ideológico.

- Unos deseos de acercamiento a UCD para la formación de la mayoría natural. 


\section{DESARROLLO DEL CONGRESO}

La apertura del Congreso se inició con unas palabras de salutación de su presidente nacional, señor Fraga Iribarne, en que destacó la lealtad de Alianza Popular a sus principios; a la Corona; a la bandera; a las instituciones, y a España, y poniendo al servicio de los españoles la mayoría natural como una invitación a la solidaridad, a la cooperación, a la eficaz inteligencia para conseguir un objetivo común.

\section{Informe del secretario general}

El secretario general, don Jorge Verstringe Rojas, presentó el informe sobre las actividades del partido, destacando tres apartados referidos a las etapas de un renacimiento; la superación de los objetivos y la emergencia de una alternativa.

A) Las etapas de un renacimiento: esta fase se inicia con el III Congreso Nacional de Alianza Popular a finales de 1979, en unos momentos especialmente difíciles, a raíz de los pobres resultados de las elecciones generales del mismo año, que hacían incluso pensar en la desaparición del partido. A partir de entonces se realizó un esfuerzo de reconstrucción y arranque, cristalizado en el IV Congreso en febrero de 1981. A partir de aquí, sucesivas elecciones han permitido consolidar el partido consiguiendo crecimientos parciales importantes, tendentes a incrementar el peso específico del partido.

B) Superación de los objetivos: a partir del IV Congreso se inició un plan de expansión, de tal suerte que a través de las urnas se consiga un peso específico parlamentario importante para los valores, principios, soluciones e intereses de la franja conservadora y reformista del pueblo español. Hoy se puede decir, según Verstringe, que los objetivos del IV Congreso han sido ampliamente superados, y que ante el cambio de fuerzas políticas se impone una redefinición de Alianza Popular. Alianza Popular ha estado presente en todos los grandes temas de la vida nacional. A continuación desarrolló, pormenorizando, las actividades internas del partido.

C) La emergencia de una alternativa: la evolución de los acontecimientos del país, caracterizado por una crisis económica ya perpetua, un paro creciente, un desprestigio de poder, lo que conlleva a una desesperanza política, se traduce, según Alianza Popular, en una oportunidad y una responsabilidad a una solución de estos problemas, desde su perspectiva conservadora y progresista, tanto más animosa cuanto los resultados electorales últimos así lo consagran por un lado, y por otro las prometedoras expectativas en futuras confrontaciones electorales que determinen a Alianza Popular como una alternativa auténtica en una España democrática.

\section{Actividades del Congreso}

El Congreso se desarrolló fundamentalmente en ponencias en las que se atacaban los problemas fundamentales que afectan al país. A continuación brevemente indicaremos la problemática y conclusiones de las ponencias más relevantes, de las que en definitiva se extrae el programa de Alianza Popular.

1. Ponencia de economía presentada por don Abel Matute: considerando como supuestos la caída del PIB, el aumento del paro, la descapitalización general, el endeudamiento público y la deficiente estructura productiva, considera imprescindible para resolver estos problemas una política presupuestaria austera que par- 
tiendo de la base de la caída real de la relación de intercambio, afrontar el problema energético, la adaptación de la estructura productiva a la crisis, la existencia de recursos necesarios del sector privado; la mejora de la gestión de la Seguridad Social y la reactivación de los sectores «locomotora». Todo ello inserto en una necesaria programación económica que evite la improvisación y dé coherencia a las necesarias actuaciones. Merece destacar la importancia de la incorporación de España a la CEE entendida como robustecimiento del bloque occidental; de la democracia y del modelo de sociedad definida en nuestra Constitución.

2. Ponencia de política energética presentada por don José Miguel González López: el problema energético viene definido, según Alianza Popular, como un condicionante del desarrollo escaso, caro y universal. Para España, el futuro hay que orientarlo hacia el ahorro energético y el máximo nivel de independencia energética.

3. Ponencia sobre el Estado de las Autonomías presentada por don José María Aznar López: los criterios básicos con los que se quiere responder a las necesidades autonómicas fundamentales, se soportan sobre la trascendencia del proceso autonómico en marcha, sobre la oportunidad de ordenar el proceso sin recurrit a procedimientos extraordinarios; sobre la necesidad de racionalizar el proceso autonómico considerando a España como una unidad, para todo lo cual se piensa en la necesidad de aprovechar en su plenitud las posibilidades que la Constitución ofrece por un lado, y en su caso mediante la reforma del artículo 2 y del título VIII de la Constitución. En esta línea se precisa que los pactos autonómicos de 1981; constituyen un intento serio y racional de encauzar el proceso autonómico. Especial atención mereció en el Congreso el sistema de financiación de las Comunidades Autónomas, pieza básica para el completo éxito del desarrollo autonómico.

4. Ponencia sobre política municipal presentada por don José Rodríguez Fernández: se considera urgente la concreción del nuevo marco jurídico local a través de una nueva ley de Administración Local de procedencia parlamentaria que junto con una nueva ley reguladora del sistema tributario local, dé soporte a la participación ciudadana y consolide la democracia en el ámbito local, al tiempo que se presta especial atención a los pequeños municipios que les permita acceder a los justos y necesarios niveles de equipamiento.

5. Ponencia de Agricultura y ponencia de Alimentación presentadas por don Antonio Velasco Navarro y por don Pablo Paños Martí: partiendo de la base de la economía libre de mercado, Alianza Popular piensa que el resurgimiento del sector agrario depende singularmente del propio esfuerzo de las empresas agrarias y no debe confiarse a la acción exclusiva del Estado. Propone la creación de equipamientos médicos integrales en las cabeceras de comarcas, la creación de un bachillerato técnico-agrícola como tránsito a estudios superiores, y un esfuerzo en obras públicas para el integral aprovechamiento de los diferentes recursos que permitan el incremento de la productividad y el desarrollo de la industria de transformación. En cuanto a los aspectos financieros, se considera imprescindible la concentración de fuentes financieras que permitan recursos adicionales a los propios del campo con una simplificación de los trámites burocráticos para acceso al crédito no sólo a corto plazo, sino a medio y largo también. Especial significación merece el tratamiento fiscal para evitar la descapitalización del sector agrario. Como complemento de la política agraria es imprescindible la ordenación del almacenamiento, transporte y comercio de los alimentos en política de precios y garantía del consumidor. De ahí la necesidad de proporcionar un marco legal de protección al consumidor, así como la ordenación y dirección de las producciones en orden a la mayor eficacia de los recursos productivos.

6. Ponencia de Cultüra, ponencia de Sanidad y ponencia de Educación Física presentadas por don José Manuel González Páramo por una parte, y por don Carlos 
Ruiz Soto, don Eduardo Rodríguez-Losada y don Higinio Casamayor Suárez, por otra, y don José A. Trujillo: Alianza Popular pretende en estas ponencias desarrollar la cultura popular entendida como el conjunto de principios y valores que constituyen un pueblo; dando prioridad al «hombre» como primer valor en su responsabilidad y libertad de ser, propicia el desarrollo de la vida personal, familiar y laboral, en un marco reformista en el que la tradición, como tesoro legado por los antepasados, debe ser transmitida a sucesivas generaciones, conservando lo válido y reformando aquello que sea necesario. Igual atención se prestará al desarrollo del deporte y su financiación en todas las edades.

En cuanto a la Sanidad, debe ser observada en el marco socioeconómico global de España, teniendo como norte la eficacia ante la disponibilidad escasa de recursos. El sistema mixto es aceptado, pero con una potenciación de la inspección para una mejor calidad; reforma de la Seguridad Social para mejorar su eficacia, controlar el gasto y regularizar la relación médico-enfermo. Especial atención a la tercera edad, toxicómanos y disminuidos físicos. Política de tratamiento de aguas, recordando su importancia coma vehículo transmisor de enfermedades $y$, por último, ordenación adecuada del sector farmacéutico.

7. Ponencia de Reforma de la Administración presentada por don Juan Ramón Calero Rodríguez: la Administración Pública exige una reforma en profundidad, tanto por razones históricas como por las derivadas de la actual reestructuración del Estado centralizado a un Estado de las autonomías y como las propias de eficacia administrativa. La reforma debe ser global, pero gradual y prudente, al tiempo que exigente con el principio de legalidad y de participación con los administrados y con los propios funcionarios dentro de la profesionalización de la función pública. Atención preferente merecen las clases pasivas.

8. Ponencia de Emigración presentada por don Guillermo Kirkpatrick: la emigración debe ser objeto de una regulación legal que, de acuerdo con la Constitución que consagra la igualdad de todos los españoles, coordine la acción del Estado en el exterior, bajo la dirección del Ministerio de Asuntos Exteriores fomentando la acción cultural y educativa del emigrante y sus hijos; canalizando de la manera más provechosa para el emigrante sus ahorros y previendo la asistencia en los problemas del retorno.

\section{Programa de Alianza Popular}

Con estas ponencias se llega a un programa de Alianza Popular en este V Congreso que, podemos pensar, constituirá la base electoral de cara a las próximas elecciones generales y que resumimos sucintamente a continuación.

Alianza Popular considera a España como nación europea y occidental con una democracia a consolidar y perfeccionar. Se integra en la línea de los partidos populistas, conservadores y reformistas de Europa. Concibe el Estado como una organización política, dotada de una Constitución que debe ser respetada sin perjuicio de los perfeccionamientos que realice el pueblo español. El Parlamento debe ser el eje vertical de la actuación política para los grandes asuntos del país que se concibe como una unidad, dentro de una descentralización autonómica armónica. Reforma de la Administración Pública progresiva y eficaz con una defensa nacional instaurada en la Constitución, con un poder judicial independiente dentro de una unidad jurisdiccional que culmina con una política exterior de incorporación a Europa, a la defensa occidental, a nuestra tradición hispánica y a la participación activa en las organizaciones internacionales.

En cuanto al modelo social, propone una activa participación y la asunción del 
cambio social a través de reformas libremente aceptadas. Las relaciones laborales se inscriben dentro del sistema de economía social de mercado, propugnando un sindicalismo libre y democrático. En cuanto a la empresa, se buscará su eficacia con especial atención a la pequeña y mediana empresa. La política de empleo tenderá a la erradicación del paro, con especial atención al acceso de los jóvenes al primer puesto de trabajo, buscando la estabilidad, sin que ello suponga rigidez de plantilla.

Se fomentará la política informativa independiente y objetiva, prestándose especial atención a la Seguridad Social, sanidad y tercera edad, dentro de las previsiones indicadas en las ponencias.

Urbanismo, política educativa, vivienda, atención a los consumidores, promoción de la mujer y especial dedicación a la juventud, completan las prioridades de Alianza Popular en su modelo social.

Por último, en cuanto a su modelo económico se caracteriza por la economía social de mercado, basado en la libre iniciativa y la participación moderada del sector público. Exige una clarificación del sector privado y sector público, devolviendo al sector público a una actividad subsidiaria.

La política económica y financiera procurará la coordinación con las economías de otros países, al tiempo que se presta atención al bienestar social y a la corrección de los desequilibrios regionales. La política y la reforma fiscal, buscarán junto a la garantía de un alto nivel de inversión y ocupación, la más justa distribución de la renta nacional y la riqueza.

Se buscará la mejora de la balanza comercial, disminuyendo el déficit de la balanza de productos agropecuarios, fomentando las exportaciones y en cuanto al sector del turismo se renovarán los esfuerzos de su promoción.

Finalmente, los sectores industrial, agrícola y pesquero, merecen un tratamiento especial, fomentando la industrialización, la corrección de los desequilibrios regionales, la reconversión industrial, la enérgica defensa de nuestros intereses pesqueros y el fomento de la industrialización agraria.

\section{Elecciones y clausura}

A continuación se procedió a la elección del Comité Ejecutivo de AP, siendo clausurado el Congreso por el secretario general y el presidente nacional, con sendos discursos de clausura, en los que, tras agradecer el esfuerzo realizado a los diversos ponentes, el señor Fraga reafirmó su fe en los objetivos del partido, refiriéndose especialmente a lo que el señor Fraga denomina mayoría natural, entendiendo por tal la agrupación de esa inmensa mayoría de españoles que quiere paz, ley, puestos de trabajo, servicios sociales a precio razonable, todo ello a través de métodos democráticos y con el convencimiento de que no hay más que un camino, que es el de la creación de las mayorías políticas que, según su criterio, la opinión y la sociedad española producen en este momento. Sin ser obstáculo el discurrir por caminos diversos, que al final pueden converger hacia ella, sin rigidez ni intransigencia, pero reconociendo que no hay otra alternativa válida para el país.

En el V Congreso de AP hubo representación de países extranjeros, con invitados de Alemania Federal (S. A. R. el archiduque Otto de Habsburgo, diputado del Parlamento Europeo); de Francia (M. Philippe Malaud, ex ministro, diputado del Centro Nacional de los Independientes; M. Jacques Ferón, Centro Nacional de los Independientes, y M. de Bausset, encargado de las relaciones internacionales del RPR); de Gran Bretaña (Sir John Rodgers, miembro del Partido Conservador Británico, y Sir Patrick Wall, parlamentario del Partido Conservador Británico y presidente de la Comisión de Defensa de los Comunes); de Dinamarca (Herr Erhard Jacobsen, 
miembro del Parlamento Europeo, presidente del Centro Democrático de Dinamarca, miembro del Comité Mixto Cortes-Parlamento Europeo, sustituto del archiduque Otto de Habsburgo en dicho Comité); de Estados Unidos (Mr. Philip M. Crane, del Partido Republicano, miembro del Congreso); de Israel (Roni Milo, del Partido Likud); de Japón (Tajima, del Partido Liberal Democrático); de Chile (Andrés Zaldívar, del Partido Demócrata Cristiano), y de Venezuela (José Marzin Kiwitro, del Partido Nueva Generación), entre otros.

M. a Victoria García-Atance 